Marquette University

e-Publications@Marquette

School of Dentistry Faculty Research and

Publications

Dentistry, School of

$11-2017$

\title{
Prosthetic Rehabilitation Following Lateral Resection of the Mandible with a Long Cantilever Implant-Supported Fixed Prosthesis: A 3-Year Clinical Report
}

Georgios Maroulakos

Marquette University, georgios.maroulakos@marquette.edu

William W. Nagy

Texas A\&M University College of Dentistry

Ayman Ahmed

Marquette University, ayman.ahmed@marquette.edu

Ioli I. Artopoulou

National and Kapodistrian University of Athens

Follow this and additional works at: https://epublications.marquette.edu/dentistry_fac

Part of the Dentistry Commons

\section{Recommended Citation}

Maroulakos, Georgios; Nagy, William W.; Ahmed, Ayman; and Artopoulou, loli I., "Prosthetic Rehabilitation Following Lateral Resection of the Mandible with a Long Cantilever Implant-Supported Fixed Prosthesis: A 3-Year Clinical Report" (2017). School of Dentistry Faculty Research and Publications. 292.

https://epublications.marquette.edu/dentistry_fac/292 
Marquette University

e-Publications@Marquette

\section{Dentistry Faculty Research and Publications/School of Dentistry}

This paper is NOT THE PUBLISHED VERSION; but the author's final, peer-reviewed manuscript. The published version may be accessed by following the link in the citation below.

The Journal of Prosthetic Dentistry, Vol. 118, No. 5 (2017): 678-685. DOI. This article is (C) Elsevier and permission has been granted for this version to appear in e-Publications@Marquette. Elsevier does not grant permission for this article to be further copied/distributed or hosted elsewhere without the express permission from Elsevier.

\section{Prosthetic Rehabilitation Following Lateral Resection of the Mandible with a Long Cantilever Implant-supported Fixed Prosthesis: A 3-year Clinical Report}

Georgios Maroulakos DDS, MS

Department of General Dental Sciences, Marquette University School of Dentistry, Milwaukee, Wis William W. Nagy DDS

Department of Restorative Sciences, Texas A\&M University College of Dentistry, Dallas, Texas Ayman Ahmed BDS, PhD

Department of General Dental Sciences, Marquette University School of Dentistry, Milwaukee, Wis Ioli I. Artopoulou DDS, MS, PhD

Department of Prosthodontics, National and Kapodistrian University of Athens, School of Dentistry, Athens, Greece 


\begin{abstract}
This clinical report describes the prosthetic management of the surgical reconstruction of a patient after mandibular resection. Complete oral rehabilitation was achieved with a maxillary complete denture and a mandibular implantsupported fixed prosthesis with a custom titanium framework and a long unilateral cantilever.
\end{abstract}

Head-and-neck cancer is estimated to represent $2.9 \%$ of all new cancer diagnoses, ${ }^{1}$ and squamous cell carcinoma (SCC) represents $96 \%$ of all oral malignancies. ${ }^{2}$ Surgical resection is considered the most common treatment for head-and-neck SCC, whereas postoperative external beam radiation therapy may be used to improve the therapeutic outcome. ${ }^{3,4,5,6,7,8,9,10}$ The microvascularized fibula flap is

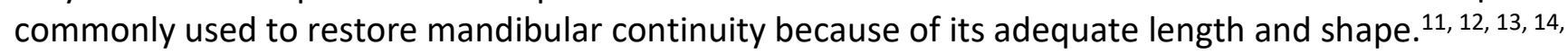
$15,16,17,18,19,20,21,22,23$ Various resection prostheses have been used for the functional rehabilitation of patients with postsurgical mandibular defects, such as conventional removable, $13,24,25,26,27,28,29,30,31$, 32,33 implant-retained and implant-supported removable, ${ }^{11,13,20,21,25,26,30,32,34,35,36}$ and implantsupported fixed prostheses. ${ }^{11,13,15,20,21,32,37,38,39,40,41,42,43}$

Osseointegrated dental implants may significantly benefit patients with surgical defects after treatment for head-and-neck cancer. $3,7,8,9,10,11,12,13,17,19,20,25,26,30,32,36$ However, reports of complete-arch fixed implant rehabilitation in patients who have undergone mandibulectomy for cancer have been sporadic. ${ }^{35}$ This clinical report describes the prosthetic rehabilitation of a patient with a history of SCC who was treated with lateral resection of the mandible and immediate reconstruction using a vascularized free fibula flap. Prosthetic rehabilitation was achieved by means of an implantsupported mandibular fixed prosthesis opposed by a maxillary complete denture.

\title{
Clinical Report
}

A 69-year-old man was referred to the Graduate Prosthodontics Clinic at Texas A\&M Health Science Center, Baylor College of Dentistry, for prosthetic rehabilitation. The patient had been treated for head-and-neck cancer 6 years before his referral. The malignancy was diagnosed as invasive moderately differentiated SCC, staged as T3N1MO.${ }^{44}$ Treatment included the right lateral resection of the mandible distal to the canine along with unilateral neck dissection and free fibula flap reconstruction. Surgical intervention was followed by photon beam radiation therapy (60 Gy to the mandible, $50 \mathrm{~Gy}$ to the lower neck). Multiple teeth were extracted before the cancer treatment. More extractions followed in the year before his referral, for which the patient received hyperbaric oxygen treatment.

Extraoral examination revealed facial asymmetry. Intraoral examination showed no mucosal lesions. Salivary gland function was reduced, and the patient had postradiation xerostomia. The mucosa lining the graft was thin and had postsurgical sensory impairment. Additionally, there was lack of labial and lingual vestibule at the reconstruction site, and tongue mobility was compromised. The remaining maxillary canines were abutments for an anterior fixed dental prosthesis. Radiographic evaluation showed the mandibular reconstruction of the right side and the presence of an impacted tooth on the maxillary left side (Fig. 1). Temporomandibular joint examination showed a reduced range of mandibular motion but no pain or discomfort. Preliminary impressions were made with irreversible hydrocolloid (Accu-Dent System 1; Ivoclar Vivadent AG). Diagnostic casts were mounted (SAM 3; SAM Präzisionstechnik $\mathrm{GmbH}$ ) with base plates and wax rims, a facebow (Axioquick Anatomic Transferbow; SAM Präzisionstechnik $\mathrm{GmbH}$ ), and a centric relation record. A diagnostic tooth arrangement was completed. 

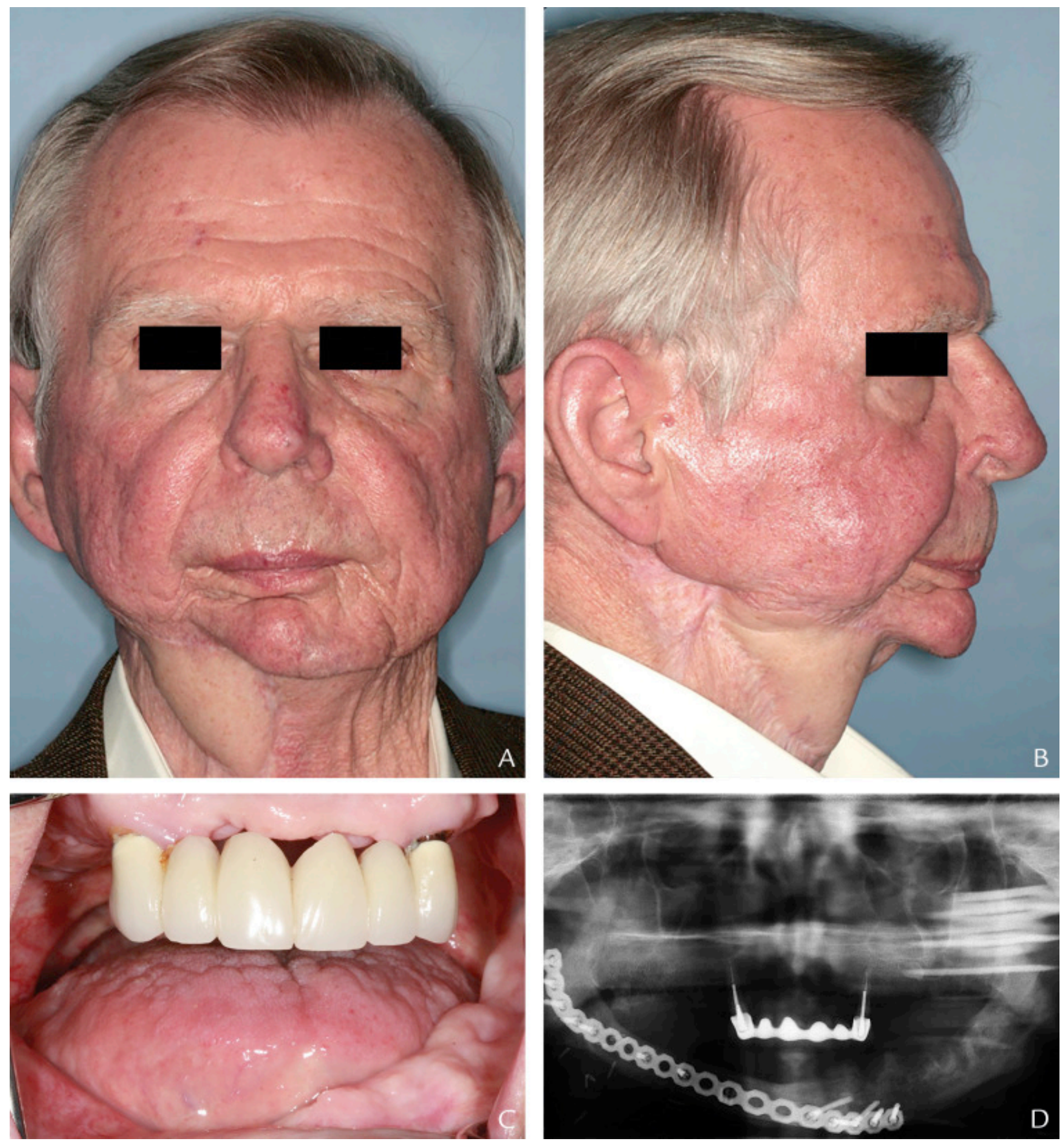

Figure 1. Pretreatment. A, Full face frontal view; note facial asymmetry as result of mandibular reconstruction after lateral mandibular resection. B, Full face, right lateral view. C, Intraoral frontal view. C, Panoramic radiograph.

The list of problems associated with the patient's periodontal, restorative, esthetic, and functional status was extensive. His oral hygiene was inadequate, and soft tissue inflammation and deep probing depths were found around his remaining teeth. The remaining teeth had a poor prognosis because of caries. The mandibular surgical reconstruction was not restoratively driven, and the existing mandibular anatomy could not provide adequate retention, stability, and support for a conventional removable prosthesis. Restorative space on the left mandibular side was inadequate for an implantsupported prosthesis. Also, his mandibular function and tongue mobility were compromised. The patient's condition was diagnosed as partial edentulism, carious infection, periodontal disease, and xerostomia. He was categorized as class IV based on the Prosthodontic Diagnostic Index for partial 
edentulism. ${ }^{45}$ Treatment objectives were to manage xerostomia, to restore the loss of teeth and soft tissues, to fabricate esthetically pleasing and functionally stable prostheses, to monitor the patient for oral cancer recurrences, and to provide the patient with an appropriate maintenance program. The existing mandibular defect, radiotherapy, and associated morbidity were factors that could negatively affect the treatment outcome.

Cone beam computed tomography was used to evaluate newly reconstructed and native bone. After consultation with the Department of Oral and Maxillofacial Surgery and a discussion of potential risks, the patient rejected any removable mandibular prosthesis and chose an implant-supported fixed mandibular prosthesis. Implant placement in the reconstructed defect side was not recommended because of radiation therapy at $60 \mathrm{~Gy}$ and the facial position of the flap in relation to the proposed tooth position. Maxillary teeth were extracted, and the left posterior mandibular ridge was reduced to provide adequate restorative space. ${ }^{46}$ Bone reduction was accomplished with a reduction guide based on the diagnostic tooth arrangement. Four implants were placed in the mandibular left first molar, second premolar, and canine locations and in the mandibular right lateral incisor location (SLActive Standard Plus RN $4.1 \times 10 \mathrm{~mm}$ and $4.1 \times 12 \mathrm{~mm}$; Straumann USA LLC) (Fig. 2). Surgical removal of the maxillary impacted tooth was contraindicated because of its location.
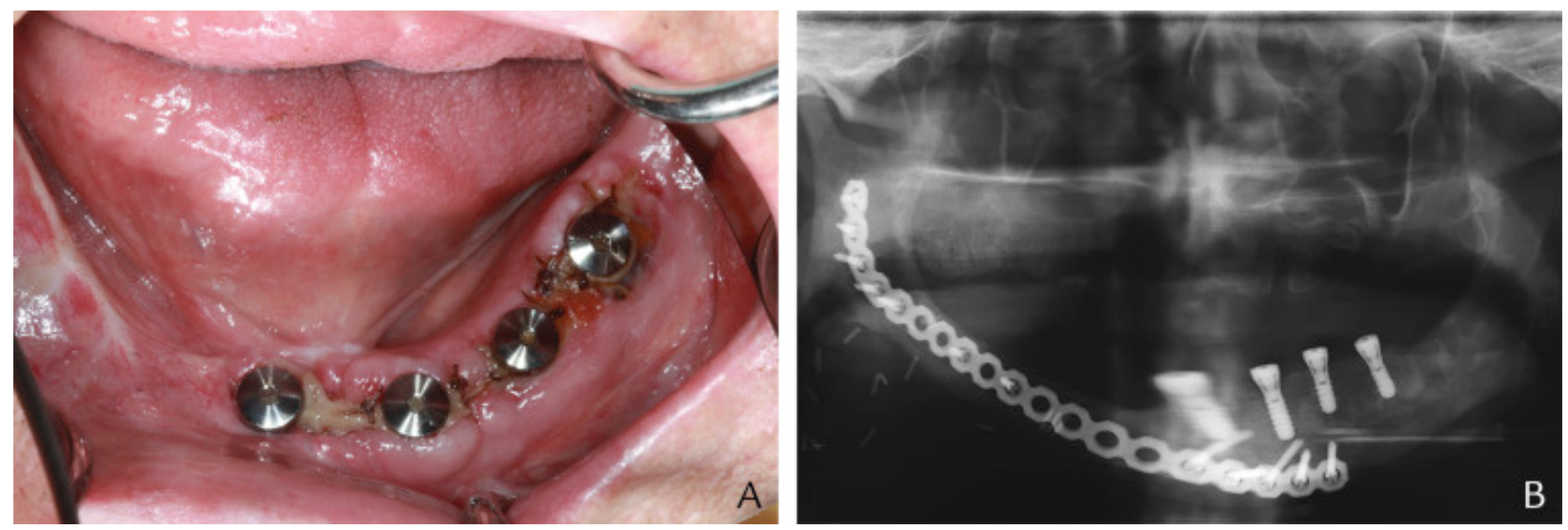

Figure 2. Implant placement. A, Intraoral view. B, Panoramic radiograph.

A maxillary interim complete denture was inserted, which was tolerated well with an oral lubricant (Oral Balance Gel; Biotène). After 6 months (Fig. 3), new diagnostic impressions were made to fabricate custom trays. The maxillary definitive impression was made with modeling plastic impression compound (Impression compound; Kerr Corp) and polysulfide impression material (Permlastic; Kerr Corp). A mandibular implant level open tray definitive impression was made with polyvinyl siloxane material (Aquasil Ultra; Dentsply Sirona). The impression copings were splinted with light-polymerizing acrylic resin (Triad Gel; Dentsply Sirona). ${ }^{47}$ The maxillary definitive cast was poured in Type III (Microstone; Whip Mix Corp) dental stone and the mandibular cast in Type IV (ResinRock; Whip Mix Corp) dental stone. The implant abutments were connected to implant analogs (RN synOcta 1.5; Straumann USA LLC), and an implant verification device was made with temporary cylinders and autopolymerizing acrylic resin (Pattern Resin; GC America). The accuracy of the device was evaluated intraorally using the 1 -screw test (Fig. 4). ${ }^{48}$ 

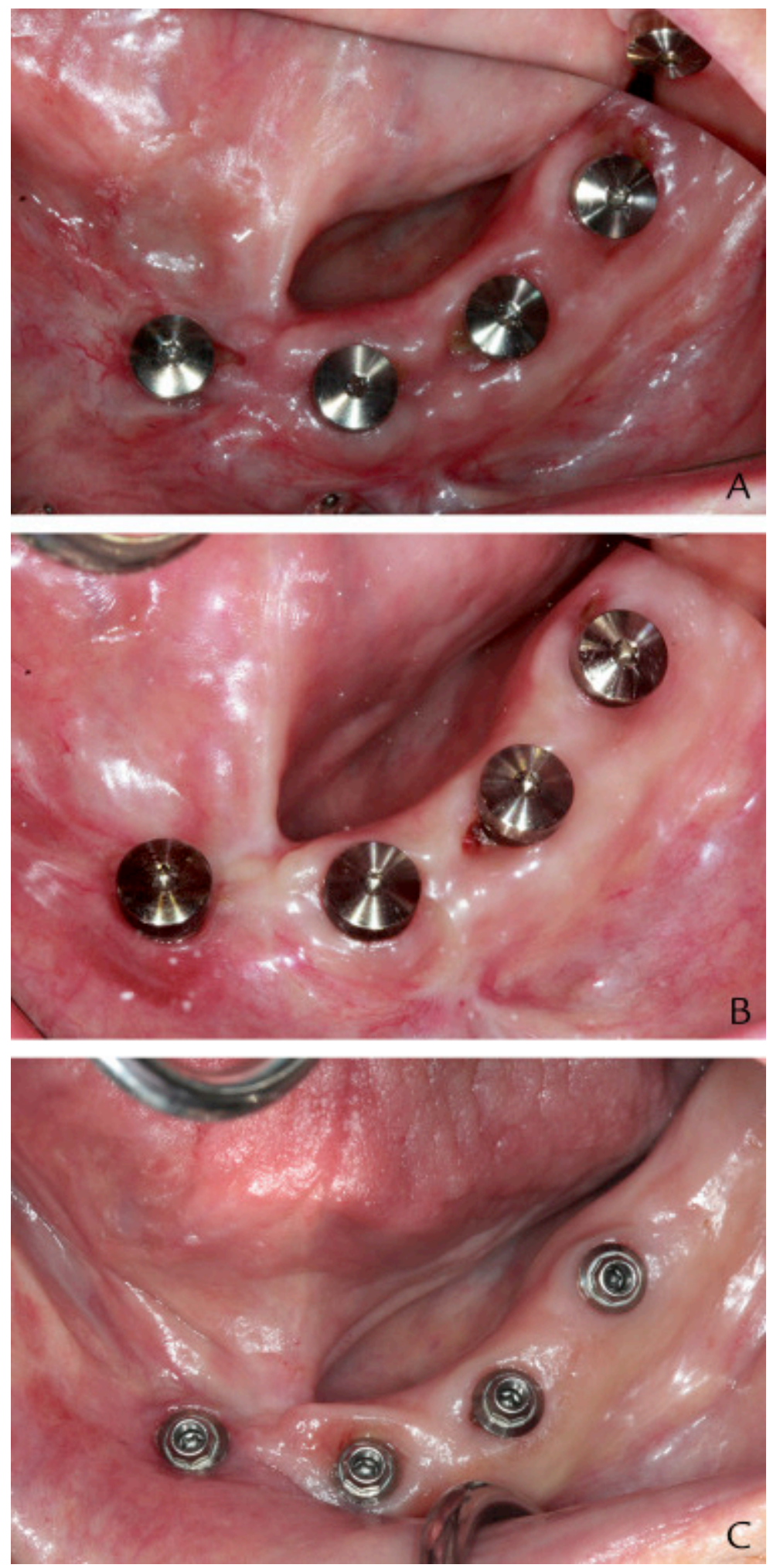

Figure 3. Peri-implant soft tissue healing. A, One-month follow-up. B, Three-month follow-up. Note slow progress of healing around implants in left molar and premolar positions. C, Six-month follow-up. Definitive abutments were placed on implants. 

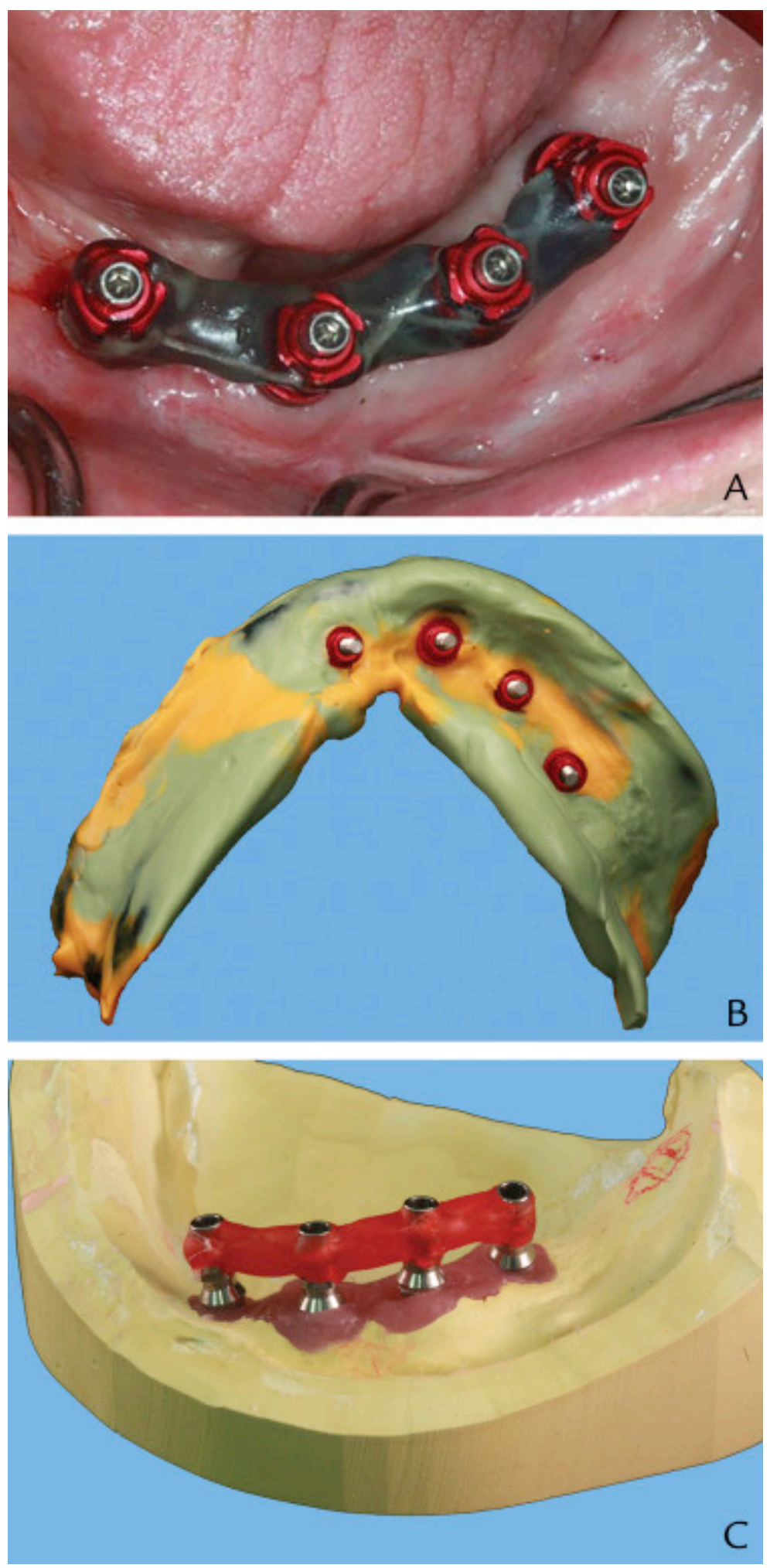

Figure 4. Mandibular definitive impression. A, Implant open tray impression copings connected with light-polymerizing acrylic resin. B, Pick-up impression. C, Definitive cast and implant verification device made with autopolymerizing acrylic resin.

Incisal edge position, occlusal plane, occlusal vertical dimension, and maxillomandibular relationship records were determined with record bases/wax rims made on the definitive casts. The artificial tooth 
arrangement was completed with semianatomic posterior teeth and was verified intraorally. A stone matrix preserved the tooth position, and a framework pattern was made with plastic copings and lightpolymerizing acrylic resin (Triad Gel; Dentsply Sirona). Adequate space for base acrylic resin was determined by the proposed tooth positions. ${ }^{46} \mathrm{~A}$ titanium alloy framework was made using the copymilling technique (CAM StructSURE; BIOMET 3i LLC). The framework accuracy was evaluated with radiographic and clinical methods. ${ }^{48}$

The definitive tooth arrangement was completed on the framework, providing bilateral balanced articulation (Fig. 5). The previously established esthetics, occlusal vertical dimension, and maxillomandibular relationship records were clinically verified. Both prostheses were processed in heat-polymerizing acrylic resin (SR Ivocap High Impact; Ivoclar Vivadent AG) (Fig. 6). The prostheses were inserted, and prosthetic screws were tightened according to the manufacturer's recommendations. Minor occlusal adjustments were made after a clinical remount. Screw access channels were covered with polytetrafluoroethylene (Teflon) tape and flowable composite resin (PermaFlo; Ultradent Products, Inc) (Fig. 7).
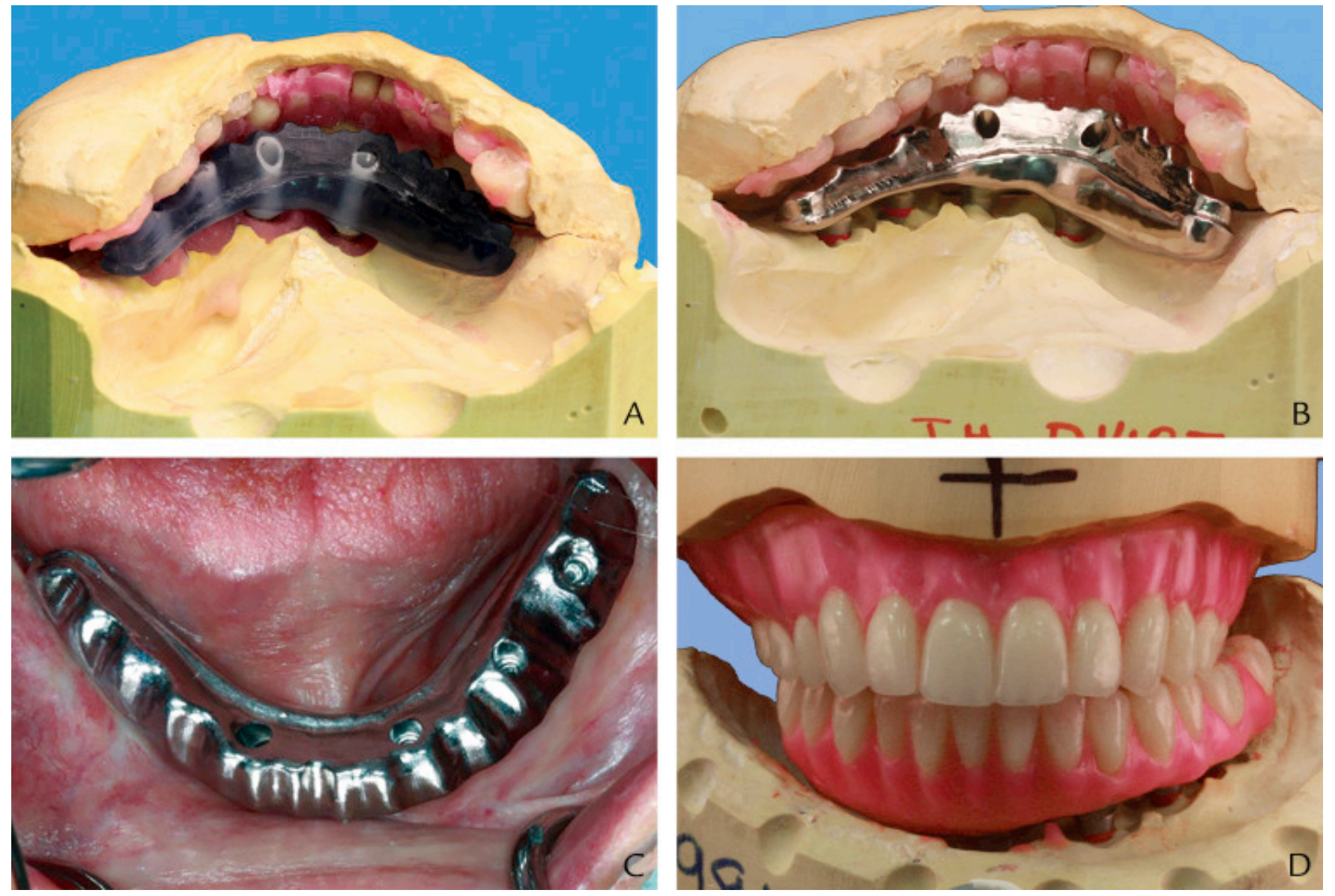

Figure 5. Mandibular framework fabrication A, Framework pattern made with light-polymerizing acrylic resin following restoratively driven approach. B, Milled titanium framework 1-piece replica of resin pattern. C, Framework evaluation. Note unilateral cantilever length. D, Definitive artificial tooth arrangement. For mandibular right side, 3 premolars were set. 

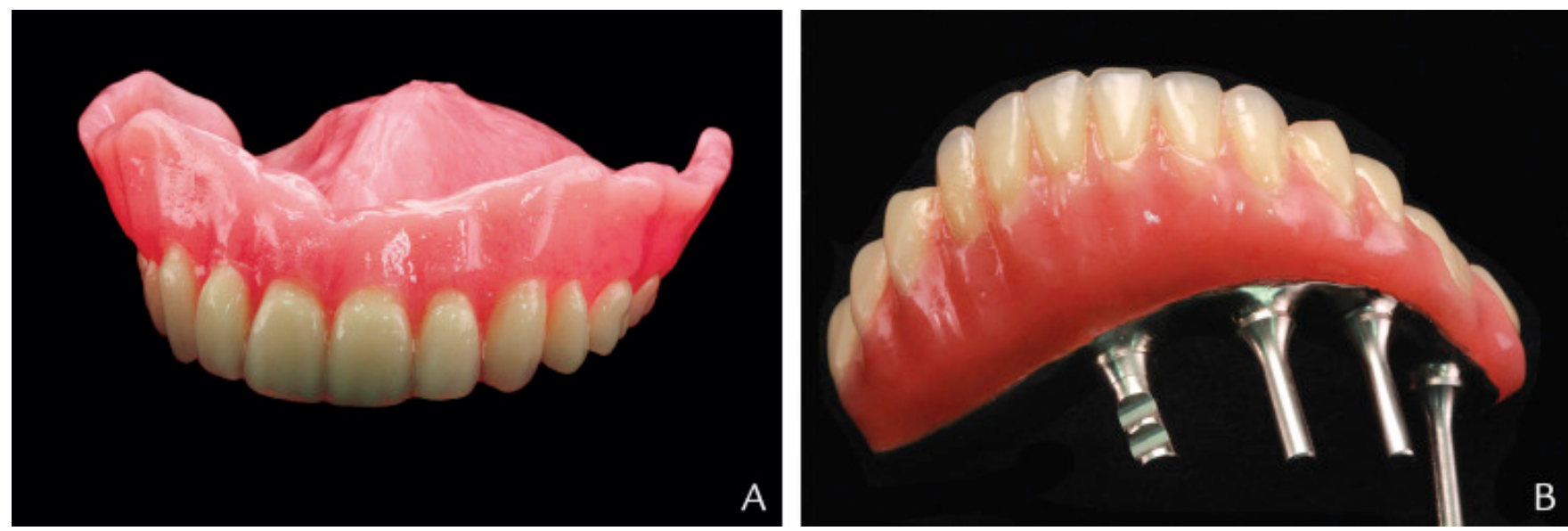

Figure 6. Processed definitive prostheses. A, Maxillary complete denture. B, Mandibular implant-supported fixed prosthesis.
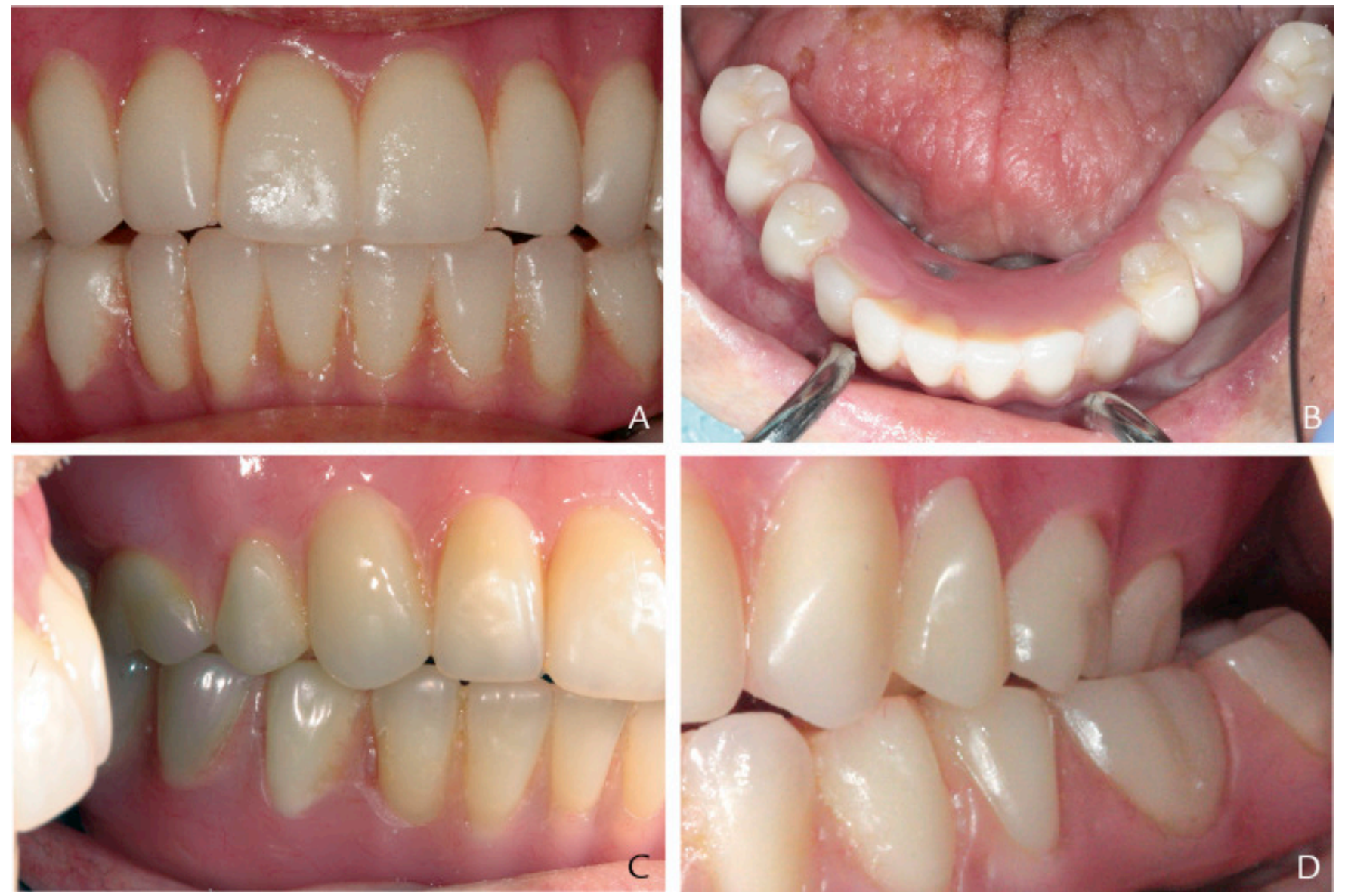

Figure 7. Definitive prostheses. A, Maximum intercuspation position, frontal view. B, Mandibular occlusal view. C, Maximum intercuspation, right lateral view. D, Maximum intercuspation, left lateral view. Note reverse articulation because of arch width discrepancy. Second mandibular molar functioned as balancing ramp.

The patient was seen 24 hours and 1 week after insertion. The prosthetic treatment did not negatively affect the patient's neuromuscular control, and the patient was satisfied with the function and the appearance of his prostheses (Fig. 8). He began a 4-month recall schedule, and at the 3-year follow-up, the prostheses and implants were stable (Fig. 9). 


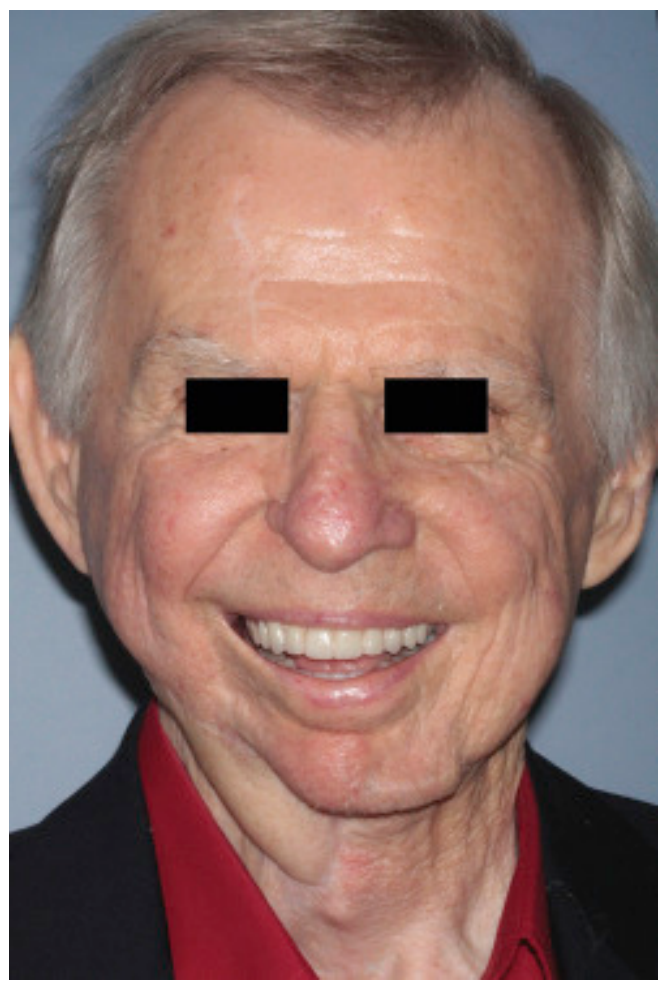

Figure 8. Posttreatment, full smile, frontal view.

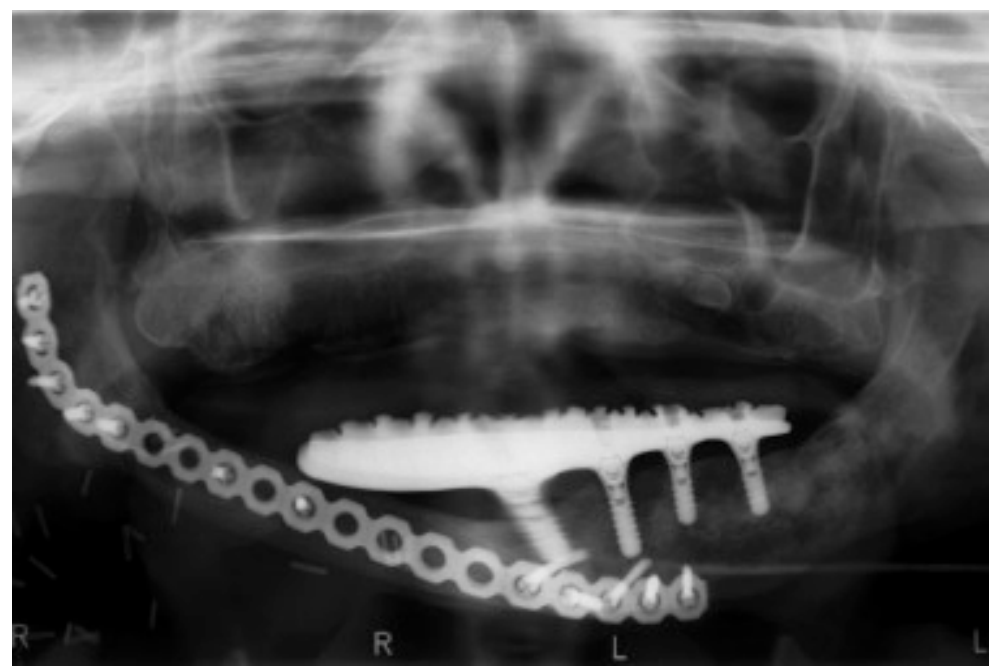

Figure 9. Panoramic radiograph at 3-year follow-up.

\section{Discussion}

Prosthetic rehabilitation with dental implants results in significant socia $\left.\right|^{11}$ and functional improvement, ${ }^{25,26,36}$ enhancing the quality of life of patients with mandibular reconstruction. ${ }^{12,32}$ Unfortunately, only a small number of patients receive implant-supported prostheses, and implant placement should be delayed for at least 12 months after ablative surgery because of the high rate of recurrence or metastasis. ${ }^{25}$

The fibula flap is a reliable option for patients with mandibular resection, as it shows low resorption during the early healing stage ${ }^{18}$ and low failure rates for the reconstructed bone, implants, and prosthesis. ${ }^{16,19,20,22}$ However, reconstructed bone combined with radiotherapy has been a negative factor for implant survival. ${ }^{7,9,22}$ The 5 -year implant survival in irradiated fibula flaps was $38 \%$, as 
opposed to $82 \%$ for irradiated mandibular bone and $86 \%$ for nonirradiated bone. ${ }^{17}$ No radiation threshold is considered safe for implant placement. Although no implant failures were observed in radiation doses lower than $45 \mathrm{~Gy}$, doses above $55 \mathrm{~Gy}$ significantly reduce implant survival.3, 8 Implant placement within 1 year after radiotherapy may result in a $34 \%$ higher risk of failure. ${ }^{10}$

Whether hyperbaric oxygen has a positive effect on implant survival is unclear. $7,8,10,49,50$ In this patient, the time interval between radiotherapy and implant placement was 6 years. However, the healing of peri-implant tissues progressed slowly and was not complete until 6 months after implant placement (Fig. 3). ${ }^{4}$ Additionally, bone resorption may be higher around implants placed in fibula flaps compared with native bone. ${ }^{13}$ Another potential problem with fibula flaps is the reduced graft height, which may result in height discrepancy with the adjacent native bone, esthetic problems, difficulty in implant placement, or difficulty using conventional removable prostheses. ${ }^{14}$ In this patient, the mandibular surgical reconstruction did not follow an interdisciplinary approach, which could optimize treatment results. ${ }^{12}$ The nonprosthetically driven mandibular surgical reconstruction resulted in a flap position that could not allow implant placement in the flap based on the proposed tooth position and without encroaching on the patient's cheek (Figs. 5, 7). ${ }^{34}$

An implant-supported fixed prosthesis was selected for this patient. However, implant distribution did not allow for a favorable anteroposterior implant spread. This resulted in an increased distal and lateral cantilever that could lead to biomechanical complications. ${ }^{51}$ The occlusal scheme chosen was bilateral balance with semi-anatomic artificial teeth. This choice resulted in a tooth arrangement that met the esthetic and functional goals of the treatment. These patients should be restored with nonanatomic teeth following the neutrocentric occlusal concept, ${ }^{52}$ which can, however, result in the absence of balanced articulation and lack of anterior vertical overlap. Evidence regarding the benefits of balanced articulation is limited, but it is the recommended occlusal concept for patients with complete dental removable prostheses. ${ }^{53}$ Lingualized occlusion could be another option but was impossible because of the present arch width discrepancy, which indicated a reversed articulation on the left side.

Despite the unfavorable implant distribution, no complications were noted at the 3-year follow-up. In addition, oral hygiene can be more difficult with fixed implant prostheses. No consensus has been reached as to which type of implant prosthesis is more successful in these patients, as the majority of evidence relies on clinical reports. ${ }^{35,37,38,39,40,41,42,43}$ Nevertheless, therapeutic outcomes can be maximized with the recent advances in guided reconstruction and 3-dimensional planning because of favorable fibula flap and implant placement. ${ }^{21,35,37,40}$

\section{Summary}

This clinical report describes the complete mouth rehabilitation of a patient with a reconstructed mandible after segmental mandibulectomy. A mandibular implant-supported fixed prosthesis with a custom-made titanium milled framework combined with a maxillary complete denture resulted in satisfactory esthetics and function.

\section{Acknowledgments}

The authors thank Dr R. Gilbert Triplett, Regents Professor and Vice Chair, Department of Oral and Maxillofacial Surgery, Texas A\&M University College of Dentistry, for performing pro bono implant surgery for this patient. 


\section{References}

${ }^{1}$ National Institutes of Health, National Cancer Institute. SEER stat fact sheets: oral cavity and pharynx cancer. NIH/National Cancer Institute, Bethesda (2017).

2 E. Omar. Current concepts and future of noninvasive procedures for diagnosing oral squamous cell carcinoma-a systematic review. Head Face Med, 11 (2015), p. 6.

${ }^{3}$ G. Colella, R. Cannavale, M. Pentenero, S. Gandolfo. Oral implants in radiated patients: a systematic review. Int J Oral Maxillofac Implants, 22 (2007), pp. 616-622.

${ }^{4}$ F. Jegoux, O. Malard, E. Goyenvalle, E. Aguado, G. Daculsi. Radiation effects on bone healing and reconstruction: interpretation of the literature. Oral Surg Oral Med Oral Pathol Oral Radiol Endod, 109 (2010), pp. 173-184.

${ }^{5}$ S. Nabil, N. Samman. Incidence and prevention of osteoradionecrosis after dental extraction in irradiated patients: a systematic review. Int J Oral Maxillofac Surg, 40 (2011), pp. 229-243.

${ }^{6}$ S. Nabil, N. Samman. Risk factors for osteoradionecrosis after head and neck radiation: a systematic review. Oral Surg Oral Med Oral Pathol Oral Radiol, 113 (2012), pp. 54-69.

7 L. Chambrone, J. Mandia Jr., J.A. Shibli, G.A. Romito, M. Abrahao. Dental implants installed in irradiated jaws: a systematic review. J Dent Res, 92 (2013), pp. 119s-130s.

${ }^{8} \mathrm{~N}$. Nooh. Dental implant survival in irradiated oral cancer patients: a systematic review of the literature. Int J Oral Maxillofac Implants, 28 (2013), pp. 1233-1242.

${ }^{9}$ E. Schiegnitz, B. Al-Nawas, P.W. Kammerer, K.A. Grotz. Oral rehabilitation with dental implants in irradiated patients: a meta-analysis on implant survival. Clin Oral Investig, 18 (2014), pp. 687698.

10 M.P. Claudy, S.A. Miguens Jr., R.K. Celeste, R. Camara Parente, P.A. Hernandez, A.N. da Silva Jr. Time interval after radiotherapy and dental implant failure: systematic review of observational studies and meta-analysis. Clin Implant Dent Relat Res, 17 (2015), pp. 402-411.

${ }^{11}$ A.C. Hundepool, A.G. Dumans, S.O. Hofer, N.J. Fokkens, S.S. Rayat, E.H. van der Meij, et al. Rehabilitation after mandibular reconstruction with fibula free-flap: clinical outcome and quality of life assessment. Int J Oral Maxillofac Surg, 37 (2008), pp. 1009-1013.

12 B. Anne-Gaelle, S. Samuel, B. Julie, L. Renaud, B. Pierre. Dental implant placement after mandibular reconstruction by microvascular free fibula flap: current knowledge and remaining questions. Oral Oncol, 47 (2011), pp. 1099-1104.

${ }_{13}$ M. Chiapasco, E. Romeo, A. Coggiola, R. Brusati. Long-term outcome of dental implants placed in revascularized fibula free flaps used for the reconstruction of maxillo-mandibular defects due to extreme atrophy. Clin Oral Implants Res, 22 (2011), pp. 83-91.

${ }^{14}$ Y. He, Z.Y. Zhang, H.G. Zhu, Y.Q. Wu, H.H. Fu. Double-barrel fibula vascularized free flap with dental rehabilitation for mandibular reconstruction. J Oral Maxillofac Surg, 69 (2011), pp. 2663-2669.

${ }^{15}$ A.R. Paranque, M. Steve, L. Vazquez, A. Bolleyn, M.A. Roze-Pellat, D.M. Dohan Ehrenfest. Esthetic and functional reconstruction of the posttumoral interrupted mandible with double-barrel fibular free flap graft: rationale for a microsurgical and prosthodontic approach. $J$ Oral Implantol, 37 (2011), pp. 571-577.

${ }^{16}$ N. Parbo, N.T. Murra, K. Andersen, J. Buhl, B. Kiil, S.E. Norholt. Outcome of partial mandibular reconstruction with fibula grafts and implant-supported prostheses. Int J Oral Maxillofac Surg, 42 (2013), pp. 1403-1408.

${ }^{17}$ C. Jacobsen, A. Kruse, H.T. Lubbers, R. Zwahlen, S. Studer, W. Zemann, et al. Is mandibular reconstruction using vascularized fibula flaps and dental implants a reasonable treatment? Clin Implant Dent Relat Res, 16 (2014), pp. 419-428. 
${ }^{18}$ C. Mertens, C. Decker, M. Engel, A. Sander, J. Hoffmann, K. Freier. Early bone resorption of free microvascular reanastomized bone grafts for mandibular reconstruction-a comparison of iliac crest and fibula grafts. J Craniomaxillofac Surg, 42 (2014), pp. 217-223.

${ }^{19}$ F. Duttenhoefer, C. Nack, C. Doll, J.D. Raguse, B. Hell, A. Stricker, et al. Long-term peri-implant bone level changes of non-vascularized fibula bone grafted edentulous patients. J Craniomaxillofac Surg, 43 (2015), pp. 611-615.

${ }^{20}$ W. Fang, Y.P. Liu, Q. Ma, B.L. Liu, Y. Zhao. Long-term results of mandibular reconstruction of continuity defects with fibula free flap and implant-borne dental rehabilitation. Int J Oral Maxillofac Implants, 30 (2015), pp. 169-178.

${ }^{21}$ R.H. Schepers, J. Kraeima, A. Vissink, L.U. Lahoda, J.L. Roodenburg, H. Reintsema, et al. Accuracy of secondary maxillofacial reconstruction with prefabricated fibula grafts using 3D planning and guided reconstruction. J Craniomaxillofac Surg, 44 (2016), pp. 392-399.

22 S. Ch'ng, R.J. Skoracki, J.C. Selber, P. Yu, J.W. Martin, T.M. Hofstede, et al. Osseointegrated implantbased dental rehabilitation in head and neck reconstruction patients. Head Neck, 38 (suppl 1) (2016), pp. E321-E327.

23 T.B. Brandao, A.J. Vechiato Filho, A.C. Prado Ribeiro, E.M. Gebrim, A.G. Bodard, D.P. da Silva, et al. Evaluation of use of acrylic resin-based surgical guide in the function and quality of life provided by mandibular prostheses with microvascular free fibula flap: A four-year, randomized, controlled trial. J Prosthet Dent, 116 (2016), pp. 457-463.

${ }^{24}$ S.H. Nakamura, J.W. Martin, G.E. King, D.C. Kramer. The labial plate major connector in the partial mandibulectomy patient. J Prosthet Dent, 62 (1989), pp. 673-675.

${ }^{25}$ N. Garrett, E.D. Roumanas, K.E. Blackwell, E. Freymiller, E. Abemayor, W.K. Wong, et al. Efficacy of conventional and implant-supported mandibular resection prostheses: study overview and treatment outcomes. J Prosthet Dent, 96 (2006), pp. 13-24.

${ }^{26}$ E.D. Roumanas, N. Garrett, K.E. Blackwell, E. Freymiller, E. Abemayor, W.K. Wong, et al. Masticatory and swallowing threshold performances with conventional and implant-supported prostheses after mandibular fibula free-flap reconstruction. J Prosthet Dent, 96 (2006), pp. 289-297.

27 P.G. Patil. Conventional complete denture for a left segmental mandibulectomy patient: a clinical report. J Prosthodont Res, 54 (2010), pp. 192-197.

28 P. Shukla, C. Hegde, N. Rampal, S. Pawah, A. Gupta, M. Shukla. Modified technique of resection denture prosthesis fabrication for a patient with segmental mandibulectomy-a case report. Eur J Prosthodont Restor Dent, 19 (2011), pp. 175-178.

29 G. McKenna, H. Ziada, P.F. Allen. Prosthodontic rehabilitation of a patient using a swing-lock lower denture after segmental mandibulectomy. Eur J Prosthodont Restor Dent, 21 (2013), pp. 141144.

${ }^{30}$ K. Fueki, E.D. Roumanas, K.E. Blackwell, E. Freymiller, E. Abemayor, W.K. Wong, et al. Effect of implant support for prostheses on electromyographic activity of masseter muscle and jaw movement in patients after mandibular fibula free flap reconstruction. Int J Oral Maxillofac Implants, 29 (2014), pp. 162-170.

${ }^{31}$ A. Bhochhibhoya, P. Shakya, S. Mathema, B. Maskey. Simplified technique for the prosthodontic rehabilitation of a patient with a segmental mandibulectomy with a hollow cast partial dental prosthesis: a clinical report. J Prosthet Dent, 116 (2016), pp. 144-146.

${ }^{32}$ V.V. Kumar, P.C. Jacob, S. Ebenezer, M.A. Kuriakose, V. Kekatpure, A.S. Baliarsing, et al. Implant supported dental rehabilitation following segmental mandibular reconstruction- quality of life outcomes of a prospective randomized trial. J Craniomaxillofac Surg, 44 (2016), pp. 800-810. 
${ }^{33}$ S.H. Mou, T. Chai, Y.Y. Shiau, J.S. Wang. Fabrication of conventional complete dentures for a left segmental mandibulectomy patient: a clinical report. J Prosthet Dent, 86 (2001), pp. 582-585.

34 A.S. Bidra, T.M. Hofstede, R.J. Skoracki, R.F. Jacob. Maxillofacial rehabilitation of a 7-year-old boy with osteosarcoma of the mandible using a free fibula flap and implant-supported prosthesis: a clinical report. J Prosthet Dent, 102 (2009), pp. 348-353.

${ }^{35}$ C. Freudlsperger, J.P. Bodem, E. Engel, J. Hoffmann. Mandibular reconstruction with a prefabricated free vascularized fibula and implant-supported prosthesis based on fully three-dimensional virtual planning. J Craniofac Surg, 25 (2014), pp. 980-982.

${ }^{36}$ R. Murase, A. Ishikawa, T. Sumida, K. Shinohara, K. Nakashiro, H. Hamakawa. Objective validity of an implant-retained overdenture with a ball attachment system after marginal mandibulectomy. Br J Oral Maxillofac Surg, 54 (2016), pp. 21-25.

37 A. Kwasnicki, L. Gartshore, C. Butterworth. Computerised dental implant rehabilitation planning and execution following mandibular resection: a case report. Eur J Prosthodont Restor Dent, 17 (2009), pp. 26-29.

38 M. Garcia Blanco, M.A. Ostrosky. Implant prosthetic rehabilitation with a free fibula flap and interpositional bone grafting after a mandibulectomy: a clinical report. J Prosthet Dent, 109 (2013), pp. 373-377.

39 H.H. Wong, E.H. Pow, W.W. Choi. Management of mandibular rotation after a mandibulectomy: a clinical report. J Prosthet Dent, 110 (2013), pp. 532-537.

${ }^{40}$ M. Mehra, T. Somohano, M. Choi. Mandibular fibular graft reconstruction with CAD/CAM technology: a clinical report and literature review. J Prosthet Dent, 115 (2016), pp. 123-128.

${ }^{41}$ H.I. Yoon, J.S. Han. Prosthetic rehabilitation with an implant-supported fixed prosthesis using computer-aided design and computer-aided manufacturing dental technology for a patient with a mandibulectomy: a clinical report. J Prosthet Dent, 115 (2016), pp. 133-136.

${ }^{42}$ R. Schneider, K. Fridrich, G. Funk. Complex mandibular reconstruction after a partial mandibulectomy with a fibula free graft: a clinical report. J Prosthet Dent, 110 (2013), pp. 223227.

43 R. Schneider, K. Fridrich, K. Chang. Complex mandibular rehabilitation of a self-inflicted gunshot wound: a clinical report. J Prosthet Dent, 107 (2012), pp. 158-162.

${ }^{44}$ A.M. Rich, B.G. Radden. Prognostic indicators for oral squamous cell carcinoma: a comparison between the TNM and STNMP systems. Br J Oral Maxillofac Surg, 22 (1984), pp. 30-36.

45 T.J. McGarry, A. Nimmo, J.F. Skiba, R.H. Ahlstrom, C.R. Smith, J.H. Koumjian, et al. Classification system for partial edentulism. J Prosthodont, 11 (2002), pp. 181-193.

${ }^{46}$ C. Drago, K. Howell. Concepts for designing and fabricating metal implant frameworks for hybrid implant prostheses. J Prosthodont, 21 (2012), pp. 413-424.

47 M. Stimmelmayr, F. Beuer, D. Edelhoff, J.F. Guth. Implant impression techniques for the edentulous jaw: a summary of three studies. J Prosthodont, 25 (2016), pp. 146-150.

48 J.Y. Kan, K. Rungcharassaeng, K. Bohsali, C.J. Goodacre, B.R. Lang. Clinical methods for evaluating implant framework fit. J Prosthet Dent, 81 (1999), pp. 7-13.

49 P. Coulthard, M. Esposito, H.V. Worthington, A. Jokstad. Therapeutic use of hyperbaric oxygen for irradiated dental implant patients: a systematic review. J Dent Educ, 67 (2003), pp. 64-68.

50 P. Coulthard, S. Patel, G.M. Grusovin, H.V. Worthington, M. Esposito. Hyperbaric oxygen therapy for irradiated patients who require dental implants: a Cochrane review of randomised clinical trials. Eur J Oral Implantol, 1 (2008), pp. 105-110.

51 M.E. McAlarney, D.N. Stavropoulos. Theoretical cantilever lengths versus clinical variables in fiftyfive clinical cases. J Prosthet Dent, 83 (2000), pp. 332-343. 
52 J. Beumer, M.T. Marunick, S.J. Esposito. Maxillofacial rehabilitation. Prosthodontic and surgical management of cancer-related, acquired, and congenital defects of the head and neck (3rd ed.), Quintessence Publishing Co, Inc, Chicago (2011), p. 137

53 I. Klineberg, S.E. Eckert. Functional occlusion in restorative dentistry and prosthodontics. Mosby, St. Louis (2016), pp. 227-230. 